\title{
BMJ open Technology adoption and implementation in organisations: comparative case studies of 12 English NHS Trusts
}

\author{
Yiannis Kyratsis, Raheelah Ahmad, Alison Holmes
}

To cite: Kyratsis $\mathrm{Y}$, Ahmad R, Holmes A. Technology adoption and implementation in organisations: comparative case studies of 12 English NHS Trusts. BMJ Open 2012;2:e000872.

doi:10.1136/

bmjopen-2012-000872

- Prepublication history for this paper is available online. To view these files please visit the journal online (http:// dx.doi.org/10.1136/ bmjopen-2012-000872).

Received 12 January 2012 Accepted 6 March 2012

This final article is available for use under the terms of the Creative Commons Attribution Non-Commercial 2.0 Licence; see http://bmjopen.bmj.com
Department of Infectious Diseases, National Centre for Infection Prevention and Management, Faculty of Medicine, Imperial College London, London, UK

Correspondence to Dr Yiannis Kyratsis: y.kyratsis@imperial.ac.uk

\section{ABSTRACT}

Objectives: To understand organisational technology adoption (initiation, adoption decision, implementation) by looking at the different types of innovation knowledge used during this process.

Design: Qualitative, multisite, comparative case study design.

Setting: One primary care and 11 acute care organisations (trusts) across all health regions in England in the context of infection prevention and control.

Participants and data analysis: 121 semistructured individual and group interviews with 109 informants, involving clinical and non-clinical staff from all organisational levels and various professional groups. Documentary evidence and field notes were also used. 38 technology adoption processes were analysed using an integrated approach combining inductive and deductive reasoning.

Main findings: Those involved in the process variably accessed three types of innovation knowledge: 'awareness' (information that an innovation exists), 'principles' (information about an innovation's functioning principles) and 'how-to' (information required to use an innovation properly at individual and organisational levels). Centralised (national, government-led) and local sources were used to obtain this knowledge. Localised professional networks were preferred sources for all three types of knowledge. Professional backgrounds influenced an asymmetric attention to different types of innovation knowledge. When less attention was given to 'how-to' compared with 'principles' knowledge at the early stages of the process, this contributed to 12 cases of incomplete implementation or discontinuance after initial adoption.

Conclusions: Potential adopters and change agents often overlooked or undervalued 'how-to' knowledge. Balancing 'principles' and 'how-to' knowledge early in the innovation process enhanced successful technology adoption and implementation by considering efficacy as well as strategic, structural and cultural fit with the organisation's context. This learning is critical given the policy emphasis for health organisations to be innovation-ready.

\section{ARTICLE SUMMARY}

Article focus

- Despite policy support and the development of a dedicated evidence dissemination infrastructure in the NHS, why is technology adoption and implementation still a challenge?

- We need to understand better how the innovation process unfolds in organisations to build on what we know about individual behaviours. In particular, how the use of different types of knowledge about an innovation impacts its adoption and implementation.

Key messages

- In our study, centralised dissemination of evidence had minimal to moderate impact on organisational innovation adoption decisions. Practice-based, peer-mediated and local dissemination systems were perceived more relevant.

- In contrast to technology adoption by individuals organisational adoption required a wider multifaceted conceptualisation of 'how-to' knowledge in line with the more complex dynamics in organisations. When 'how-to' knowledge was undervalued and considered late, important strategic, structural and cultural elements of the trust's context were overlooked. This had negative implications for technology adoption and implementation.

- Professional backgrounds of those involved in the process influenced the types of innovation knowledge considered, which had implications for implementation. The involvement of diverse professionals in decision-making improves the chances of successful implementation through a balanced consideration of the strength of scientific evidence and practical application.

\section{INTRODUCTION}

The recent focus on quality and efficiency in healthcare by policy makers ${ }^{1}$ highlights the need to harness new healthcare technologies and innovation to improve quality of patient 


\section{ARTICLE SUMMARY}

\section{Strengths and limitations of this study}

- The scale of the study, its real time and longitudinal nature provide a rich data set. Our study is theory driven and comprises multisite comparative case studies, which enhance the generalisability of findings beyond the context of the studied trusts.

- We explicitly studied cases of non-adoption and discontinuation after initial adoption to provide important learning often missing from innovation diffusion research.

- On limitations, we were not able to follow implementation past the end of August 2010 and therefore do not have information on routinised use of the implemented technologies.

care and health system productivity. ${ }^{23}$ The uptake and implementation of new technologies in healthcare has often proved challenging and in some cases very slow. ${ }^{4-6}$ In the UK, the significant 'research to practice' knowledge gap and the suboptimal implementation of new ideas and technologies into clinical practice have been emphasised in several recent policy documents. ${ }^{7-9}$ Policy and academic systematic reviews ${ }^{6}{ }^{10}$ consistently show that there remains a poor understanding of the mechanisms and processes that encourage the adoption of new interventions. Specifically, attention to the processes by which organisational members access and use implementation and clinical evidence during decision-making is required. ${ }^{9}{ }^{11}$ As regards technology adoption in the NHS, a recent systematic review ${ }^{12}$ has found that there has been little research in this area.

In the last decade, government-funded agencies have been created to encourage innovation uptake and promote the use of evidence-based innovations in the NHS $^{1}{ }^{13}$; such predominately centralised evidence dissemination structures include the NHS Institute for Innovation and Improvement, the National Institute for Health and Clinical Excellence with the launch of the NHS Evidence online portal and the NHS Technology Adoption Centre, which works to speed-up the adoption of proven technologies by NHS organisations. Despite these initiatives, the challenges of adopting novel technologies in the NHS persist.

Our study addresses this research gap and is well grounded in innovation change and diffusion theories. ${ }^{14-16}$ Specifically, our study unpacks the innovation processes in organisations - in contrast to individualsby investigating in detail the interplay between the types and sources of innovation knowledge used. We empirically focus our investigation on infection prevention and control (IPC) as it represents a cross-cutting priority area in healthcare with application to primary and acute care, surgery and medicine alike. While there has been increasing public and policy attention to address healthcare-associated infections (HCAIs) (box 1), the uptake and implementation of new technologies in IPC varies and remains slow. ${ }^{24}$ This empirical setting, therefore, offers opportunities to generate transferable lessons.

\section{METHODS}

\section{Design and theoretical approach}

This article reports on findings from a larger innovation adoption study in the area of HCAIs commissioned by the Department of Health (DH). ${ }^{25}$ We employed a multiple case study research design to build theory inductively ${ }^{26}$ covering the decision-making, procurement and implementation processes by NHS organisations when introducing innovative technologies. We undertook comparative case studies ${ }^{27}$ across 12 NHS trusts in England with each trust and technology adoption decisions as units of analysis. Consistent with our research aims, we employed interpretive methods of enquiry, which allows description, interpretation and explanation of a phenomenon rather than estimation of its prevalence. ${ }^{28}$

Damanpour and Schneider ${ }^{14}$ suggest that the process of innovation adoption in organisations can be divided into three broad phases of 'pre-adoption', 'adoption decision' and 'post-adoption', also referred to in the

Box 1 Healthcare-associated infections (HCAls) initiatives in the NHS

HCAls are a worldwide problem causing high mortality and morbidity with significant cost implications for health systems. ${ }^{17-22}$ Both developing and more developed countries face the challenge, ${ }^{18}$ and there is intense media and public attention on the issue. In the UK, a range of infection prevention and control policies have been introduced to help tackle the problem, including legislation, performance targets and clinical guidelines. In England, the reporting of meticillin-resistant Staphylococcus aureus bloodstream infections and Clostridium difficile infections are mandatory, and there are national and local targets for reduction as well as national evidence-based guidelines. ${ }^{23}$ The development of effective technology interventions to complement good infection control practice is viewed as central to tackling HCAls, and a range of evidence-based innovations have been developed. Government-funded programmes, such as the Department of Health 'HCAI Technology Innovation Programme', ${ }^{24}$ have been created to fast-track the innovation process. Programme work streams span development to procurement and implementation processes and include: 'Smart Ideas', 'Design Bugs Out', 'Smart Solutions', 'Product Surgeries' and 'Showcase Hospitals', the latter focusing on the in-use value of HCAl technologies. In addition, the Health Protection Agency Rapid Review Panel was set up in 2004 to review new HCAl-related technologies providing a prompt assessment of new and novel equipment, materials and other products or protocols that may be of value to the NHS to help reduce HCAI rates; recommendation statements about the novel products are given to suppliers and NHS bodies ('Recommendation 1' being the highest, encouraging adoption by the NHS). 
literature as 'initiation', 'adoption (decision)' and 'implementation'. ${ }^{13} 1526$ In this article, we use the latter terminology. Adoption is viewed as a process in which organisational members analyse the potential benefits and negative aspects of an innovation on the basis of gathered knowledge. During this process, three types of innovation knowledge are important in moving potential adopters from 'ignorance' through awareness, attitude formation, evaluation and on to adoption - 'the decision to make full use of the innovation as the best course of action available ${ }^{, 15}$ :

1. Awareness knowledge-the awareness that an innovation exists and knowledge of its key properties.

2. How-to knowledge-the information necessary to use an innovation properly.

3. Principles knowledge-information dealing with the functioning principles underlying how the innovation works.

The above definitions of innovation knowledge may be relatively simple and consistent when applied to technology adoption by individuals, while they become ambiguous when applied to the organisational setting in which the process is complex and contested. ${ }^{12} 29$ Evidence is a form of knowledge and in this article comprises empirical, theoretical and experiential ways of knowing. ${ }^{30}$

\section{Sampling and settings}

The study comprised one primary and 11 acute care organisations (NHS trusts), across all 10 Strategic Health Authorities in England. The trusts included in the study sample were diverse in geography, size and type (table 1). The sample was predefined with one attribute in common as recipients of DH's 'HCAI Technology Innovation Award for outstanding contributions to fighting infections 2009'. The trusts were nominated by each Strategic Health Authority on the basis of having excelled in either turnaround or 'best in class' concerning infection prevention performance in the fiscal year 2008/2009. The trusts were given free reign to use the sum to procure technologies that could help reduce HCAIs (awarded in February 2009).

\section{Data collection and participants}

We collected data from secondary sources to provide a historical dimension to better situate the studied decision-making processes.

Data from primary sources comprised 121 semistructured individual and group interviews carried out during the 18 months (July 2009-August 2010). On average, this equates to 10 hour-long interviews per trust. Twelve informants were interviewed more than once. Depending on the number and scope of technologies, we conducted between two to five visits per trust. Within each of the trust sites, we purposively sampled a diverse range of informants involved in the technology adoption or implementation, reflecting various perspectives, professional and organisational roles. Our participants included clinical and non-clinical managers, members of trusts' executive boards, health professionals, staff from estates and facilities and IPC teams comprising: Director of Infection Prevention \& Control (DIPC), deputy DIPC, medical microbiologist, infection doctor, infection control nurses (the most populous group), surveillance staff, decontamination lead. Some IPC teams included a pharmacist or infection control matrons.

Interviews explored individuals' perceptions, experiences and views on the technology selection decisions, procurement and implementation processes. In the first visit, the ongoing decision-making process was captured, and in follow-up visits, technology selection outcome and implementation experiences were explored. Field notes were taken during observation of technologies inuse and relevant meetings. Observation was used to familiarise with technologies and context, and triangulate interview data. For example, in one trust,

Table 1 Case study sites characteristics

\begin{tabular}{|c|c|c|c|c|c|c|c|}
\hline Trust & Trust type & $\begin{array}{l}\text { Number of } \\
\text { beds }\end{array}$ & $\begin{array}{l}\text { Population } \\
\text { covered }(\mathrm{m})\end{array}$ & $\begin{array}{l}\text { Financial } \\
\text { turnover (m) }\end{array}$ & $\begin{array}{l}\text { Number of } \\
\text { sites }\end{array}$ & $\begin{array}{l}\text { DIPC } \\
\text { profession }\end{array}$ & $\begin{array}{l}\text { Number of } \\
\text { technologies } \\
\text { adopted }\end{array}$ \\
\hline $\mathrm{T} 1$ & S, PFI & 1269 & 0.75 & $£ 400$ & Multisite & Medical doctor & 1 \\
\hline $\mathrm{T} 2$ & $\mathrm{~S}, \mathrm{~F}, \mathrm{PFI}$ & 754 & 0.34 & $£ 156$ & Multisite & Medical doctor & 6 \\
\hline T3 & $\mathrm{T}, \mathrm{U}$ & 1902 & $1(\mathrm{~S}), 3(\mathrm{~T})$ & $£ 652$ & Multisite & Medical doctor & 1 \\
\hline $\mathrm{T} 4$ & $\mathrm{~T}, \mathrm{U},(\mathrm{PFI})$ & 988 & $0.5(\mathrm{~S}), 1.5 \mathrm{~m}(\mathrm{~T})$ & $£ 420$ & Multisite & Medical doctor & 3 \\
\hline T5 & $\mathrm{T}, \mathrm{U}, \mathrm{F},(\mathrm{PFI})$ & 2068 & $0.5(\mathrm{~S}), 1.7(\mathrm{~T})$ & $£ 648$ & Multisite & Medical doctor & 3 \\
\hline T6 & $\mathrm{S}, \mathrm{PFI}$ & 1095 & 0.6 & $£ 430$ & Multisite & Medical doctor & 2 \\
\hline T7 & $\mathrm{S}, \mathrm{F},(\mathrm{PFI})$ & 602 & 0.35 & $£ 200$ & One site & Medical doctor & 4 \\
\hline $\mathrm{T}^{*}$ & $\mathrm{~T}, \mathrm{U}, \mathrm{F}$ & 807 & $0.33(\mathrm{~S}), 1.5(\mathrm{~T})$ & $£ 250$ & One site & Nurse & 3 \\
\hline T9 & $\mathrm{T}, \mathrm{F},(\mathrm{PFI}), \mathrm{U}$ & 1150 & $0.12(\mathrm{~S}), 1 \mathrm{~m}(\mathrm{~T})$ & $£ 440$ & Multisite & Nurse & 3 \\
\hline $\mathrm{T} 10$ & $\mathrm{~S},(\mathrm{U})$ & 974 & 0.6 & $£ 415$ & Multisite & Medical doctor & 4 \\
\hline $\mathrm{T} 11^{*}$ & $\mathrm{~T}, \mathrm{U}, \mathrm{F}$ & 802 & $0.3(\mathrm{~S}), 1.5(\mathrm{~T})$ & $£ 400$ & Multisite & Nurse & 3 \\
\hline $\mathrm{T} 12^{*}$ & $\mathrm{P} / \mathrm{I}$ & $76(I)$ & 0.43 & $£ 202(\mathrm{P}), £ 744(\mathrm{~S})$ & Multisite & Nurse & 5 \\
\hline
\end{tabular}


a technology reported in interview accounts as 'fully implemented' was not verified as such during observation visits to implementation wards. A total of $20 \mathrm{~h}$ of observation were completed, on average $30 \mathrm{~min}$ per technology. Data collection at each site continued until all aspects of the decision process had been accounted for by a diverse sample of informants.

\section{Data analysis}

We analysed data using an integrated approach. ${ }^{31}$ Development of codes was initially derived from the primary data ('ground-up'), subsequently complemented with an organising conceptual framework for the adoption of complex health innovations. ${ }^{31}$ This framework has been previously employed to understand multilevel innovation adoption. ${ }^{32}$ Data analysis was conducted in parallel to ongoing data collection to feed emerging findings and 'test' these in subsequent interviews. The Qualitative Data Analysis computer software package N-Vivo 8 (QSR International) was used to systematically code the data and assist analysis, especially in cataloguing and linking concepts and codes. In line with recommendations by qualitative methodologists, ${ }^{33-35}$ Yiannis Kyratsis (author 1) and Raheelah Ahmad (author 2) independently coded all data. The three authors met to review discrepancies, ${ }^{31}$ enhancing internal validity. ${ }^{35-37}$ Comparative cases were analysed in two stages: first each of the technologies within each trust, producing individual trust case studies; second, a comparative analysis across the trusts. Summary tables were used to reduce the volume of primary data and to make analytical inferences by comparing and contrasting pairs and groups of cases. ${ }^{26}$ We defined the outcomes of the technology adoption process as follows: 'successful adoption'-the organisational executive decision to make full use of a technology, which results in procurement; 'successful implementation'-the technology is put into use and operationalised.

\section{MAIN FINDINGS}

\section{The organisational innovation process and outcomes}

Of the 38 organisational technology adoption decisions made during the period of the study, 22 technologies were successfully adopted and implemented, while 12 were discontinued after initial adoption or only partially implemented (table 2). There was no clear outcome within the time frame of the study for four technologies. The nature of technologies is described in detail elsewhere. ${ }^{25}$ A general typology of technologies isolated from context did not provide insights to likelihood of adoption. As illustrated in table 2, the same technologies (ie, the Hydrogen Peroxide Vapour System or the ATP Hygiene Monitoring System) in diverse trusts and at different stages of the innovation process resulted in differential outcomes. Most informants reported that they went through a series of evaluations, choices and actions over time as the adopting trusts principally engaged in a problem-solving exercise. The process was dynamic, iterative and not always linear. The IPC team and some wider staff were involved in adoption decisions. While the formal executive decision lay with the DIPCs, they were not always the key decision makers across the cases. The size and professional composition of the IPC teams, and the professional background of the DIPC (table 1), varied. We found that the majority of technology decisions were led by a perceived need-an area of priority in IPC had been identified by trusts first and then relevant technologies were sought ('need pull'). A minority of technology adoption decisions were characterised by selecting a technology in the first instance and exploring how this might fit with strategic plans and service needs ('technology push').

\section{Use of innovation knowledge in the organisational setting}

Trusts variably accessed and prioritised the three types of innovation knowledge in the organisational setting, and these comprised a much broader, multidimensional definition compared with a simpler definition when the potential user is an individual. ${ }^{15}$ Under 'awareness' knowledge, the trusts considered the range of technologies available to address a particular problem, as well as key features and potential cost implications of such technologies. In seeking 'principles' knowledge, the trusts sought primarily evidence of the technologies' technical efficacy based on the scientific principles behind the technology. They assessed the validity of claims made by commercial suppliers. In the 'how-to' knowledge, the trusts sought knowledge about the practical application of the technologies in local healthcare settings with nine trusts trialling the technologies. This included users' experience with the technologies, aesthetics, functionality as well as compatibility with strategic, structural and cultural elements of the trust's context. A more detailed estimation of the short-term and long-term associated costs also constituted 'how-to' knowledge. Cost and effectiveness issues permeated the three types of innovation knowledge. The definition of effectiveness was broader when both 'principles' and 'how-to' knowledge were given sufficient attention and this ranged from local opinion, including patient perceptions, ease of use by staff, to experimental controlled trials data. The majority of informants from all trusts noted that no particular technology could be solely or directly attributable to reducing HCAIs, and impact was attributable to ongoing multifaceted approaches.

\section{Centralised and local dissemination of innovation knowledge}

Those involved in decisions used a wide range of sources to get information on the three types of innovation knowledge (table 3). Peer review journals and commercial suppliers were used in all trusts to source 'principles' knowledge. Supplier information was reported as compact and easy to access for practitioners; however, this source was viewed as less credible. Of the 
Table 2 The stage when 'how-to' knowledge was first considered in the process and associated outcome

Initiation
Infection Manager Software (T6) $\rightarrow$
Successful adoption and implementation
Urinary Catheter Care Bundle (T1) $\rightarrow$
Successful adoption and implementation

Successful adoption and implementation

Endoscopy sinks (T2) $\rightarrow$ Successful

adoption and implementation

Real-time PCR for Norovirus testing

$(\mathrm{T} 2) \rightarrow$ Successful adoption and

implementation

Hydrogen Peroxide Vapour System

$(\mathrm{T} 12) \rightarrow$ Successful adoption and implementation

ATP Hygiene Monitoring System

$(T 11, T 12) \rightarrow$ Successful adoption

and implementation

Microbiology testing: mass

spectrometry analysis machine

(T5) $\rightarrow$ Successful adoption and

implementation

Digital Count up posters/boards

(T8) $\rightarrow$ Successful adoption and

implementation

Portable PC Tablets (T6, T8) $\rightarrow$

Successful adoption and

implementation

Individual Patients MRSA

Decolonisation Pack (T11) $\rightarrow$

Successful adoption and

implementation

Single use disposable Blood Pressure

Cuffs and Pulse Oximeter Probes

$($ T7) $\rightarrow$ Successful adoption and

implementation

UV light hand inspection kit (T12) $\rightarrow$

Successful adoption and

implementation

NB, Four technologies are excluded in the table as there were no clear outcomes within the time frame of the study.

MRSA, meticillin-resistant Staphylococcus aureus.

government-funded centralised evidence dissemination structures, DH Showcase Hospitals Programme was widely used by trusts for obtaining 'awareness' and 'howto' knowledge, but none of the trusts used it for 'principles' knowledge. Local expert advice was preferred to the dedicated central expert panel (Rapid Review Panel) for obtaining 'principles' knowledge, while guidelines were used by only three trusts. Professional networks consistently featured among the top sources for all three types of innovation knowledge. The latter were used to exchange experiences on the use of the same or similar technologies, spreading information horizontally via networks of peers and local experts.

\section{Critical timing of innovation knowledge use}

We found that at the earlier stages of the process, 'principles' knowledge was given more attention overlooking important aspects of 'how-to' knowledge. When 'how-to' knowledge was considered late, there were negative implications for the adoption and implementation of the technologies (table 2). For example, 'how-to' knowledge was not considered early on in Trust 
Table 3 Type and sources of innovation knowledge used in the technology adoption process per trust

\begin{tabular}{|c|c|c|c|}
\hline $\begin{array}{l}\text { Types of innovation } \\
\text { knowledge } \\
\text { Sources of innovation } \\
\text { knowledge }\end{array}$ & $\begin{array}{l}\text { Awareness knowledge: } \\
\text { identify technologies } \\
\text { available to specific IPC } \\
\text { priority areas and } \\
\text { information about the } \\
\text { nature of these } \\
\text { technologies }\end{array}$ & $\begin{array}{l}\text { Principles knowledge: why } \\
\text { and how a technology } \\
\text { works in terms of the } \\
\text { underlying scientific } \\
\text { principles or theory }\end{array}$ & $\begin{array}{l}\text { 'How-to' knowledge: how to } \\
\text { put the technology in use, } \\
\text { including issues of } \\
\text { compatibility with trust } \\
\text { structures/strategy/culture } \\
\text { and issues of sustainability }\end{array}$ \\
\hline $\begin{array}{l}\text { Professional networks/other } \\
\text { NHS trusts }\end{array}$ & $\mathrm{n}=11$ & $n=7$ & $n=10$ \\
\hline Peer review journals & $\mathrm{n}=2$ & $\mathrm{n}=12$ & - \\
\hline Hospitals outside UK & $\mathrm{n}=1$ & - & - \\
\hline Commercial supplier & $\mathrm{n}=6$ & $\mathrm{n}=12$ & $\mathrm{n}=11$ \\
\hline $\begin{array}{l}\text { Previous experience of } \\
\text { other technologies }\end{array}$ & - & - & $\mathrm{n}=5$ \\
\hline $\begin{array}{l}\text { Previous experience of } \\
\text { same/similar technology }\end{array}$ & $\mathrm{n}=6$ & - & $\mathrm{n}=6$ \\
\hline $\begin{array}{l}\text { Showcase Hospitals } \\
\text { Programme }\end{array}$ & $n=7$ & - & $n=8$ \\
\hline Rapid Review Panel (RRP1) & $\mathrm{n}=7$ & $\mathrm{n}=1$ & - \\
\hline Expert advice & $\mathrm{n}=7$ & $\mathrm{n}=4$ & - \\
\hline Own research/evaluation trial & - & $\mathrm{n}=2$ & $\mathrm{n}=3$ \\
\hline $\begin{array}{l}\text { DH dissemination- } \\
\text { conferences, websites }\end{array}$ & $\mathrm{n}=5$ & $n=1$ & - \\
\hline Internet & $\mathrm{n}=1$ & - & - \\
\hline Guidelines & - & $\mathrm{n}=3$ & - \\
\hline
\end{tabular}

$\mathrm{n}$, number of trusts (out of a total population of 12 trusts studied).

4 for the ultraviolet light air sterilisation units, and consequently, the technology was discontinued after initial adoption. Hidden running costs, such as replacing costly bulbs and filters regularly, as well as the practicality of assembling units on site, were overlooked. Conversely, when 'how-to' knowledge was considered earlier by decision makers, successful technology adoption and implementation was evident. The 14 technology cases for which 'how-to' knowledge was first considered during the 'initiation' stage were all adopted and implemented successfully. The 10 technology cases for which 'how-to' knowledge was first considered during the 'adoption decision' stage, mainly during pre-adoption evaluation trial, resulted in informed organisational decisions to either adopt or reject technologies; and for those technologies adopted led to subsequent successful implementation. For the 10 technology cases where 'how-to' knowledge was first considered during 'implementation', uptake was challenging leading to unsuccessful implementation following initial adoption.

Looking in more detail at an example where 'how-to' knowledge was inadequately considered in the early stages of the process is that of ultrasonic cleaning tanks in Trust 5:

[the technology] was very definitely sold as a replacement for manual cleaning...we embarked in the belief that using the tank would mean that when the equipment came out at the other end and was dried it would be safe to use on the next patient...we didn't feel comfortable [after having tested the tanks for bacteria levels in water after cleaning] and we felt that to make these pieces of equipment safe we would then manually go over them with a disinfectant... and this means additional workload [Senior IPC Nurse]

Important aspects of structural incompatibility only came to light during implementation. The water in the tanks needed to be replaced after each cleaning session, refilled and water heated overnight. This added to the hospital staff workload. The tanks needed to be hardwired for electricity, which meant no manoeuvrability-the initial plan had been to move the tanks around the hospital rather than shift dirty and bulky items to the tanks. The technology though purchased by the trust, resulted in becoming obsolete; the tanks were housed by estates in a storage area on the top floor of the hospital and used in a very different way from the original plan.

An example where detailed attention was given to 'how-to' knowledge during the 'adoption decision' stage informed subsequent purchases of infection control computer keyboards and mice (fully enclosed and flat design enabling quick and thorough cleaning) used with Picture Archiving and Communication Systems in clinical areas. In Trust 8 , feedback from chest consultants (principal users of the technology) resulted in appropriate procurement of computer devices, which were consistent with working practices as well as compliant with infection prevention guidelines:

Had we not changed [the newly introduced] flat computer mouse to replace it with one that has got a push scrolling button, the targeted users would not have used it at all; it is highly likely that they would have 
replaced them with normal computer mouse instead... [Trust 8]

\section{The influence of professional background and organisational type}

We found variation in the priority given to the type of innovation knowledge across professional groups. Nurse professionals involved in adoption decisions reported taking an approach where careful focus on 'principles' knowledge was balanced with adequate attention to 'how-to' knowledge. Conversely, medical professionals always prioritised 'principles' knowledge. Consistently across the trusts, consultant microbiologists, clinical matrons and infection control nurses looked at the same technologies differently and came to divergent decisions regarding the value of specific technologies. Specifically in $\mathrm{T} 4, \mathrm{~T} 6, \mathrm{~T} 7, \mathrm{~T} 10, \mathrm{~T} 11$, the clinical microbiologists valued almost exclusively 'principles' knowledge to judge the effectiveness and appropriateness of technologies for the trusts. Clinical microbiologists across trusts, looked primarily at peer-reviewed published articles for such information. In contrast, clinical matrons preferred more applied information about technology effectiveness and would discount solely technical accounts, as the following quote illustrates:

\footnotetext{
'You don't want such jargonistic information. You need to make it very simple to say this is how it works. These are the benefits, blah, blah, blah, rather than going to such, you know, higher level of microbiology" [Clinical Matron].
}

An IPC nurse in the same trust highlighted the importance of combining 'how-to' and 'principles' knowledge to assess effectiveness and appropriateness of the technologies:

You need both evidence from [peer review] papers and the practicality of using the product [in the local context]. It's very important [IPC Nurse].

Trusts affiliated with universities, comprising research active organisations (T3, T4, T5, T8, T10, T11-also see table 1), prioritised and systematically searched for scientifically produced 'principles' knowledge. This attitude was mirrored across professional groups, though was more pronounced in accounts by respondents from the medical profession.

\section{DISCUSSION}

\section{Main findings}

We found the technology adoption process to be highly dynamic and iterative. Adoption decisions entailed the acquisition and processing of new knowledge by organisational members who sought to reduce uncertainty about an innovation. Trying to find solutions to problems was the key motivator for sourcing evidence across the cases.

Scientifically produced 'principles' knowledge was prioritised by those involved in decisions to judge effectiveness of technologies. Empirical and experiential types of knowing were also widely used to judge the effectiveness and appropriateness of the technologies in the local setting but were often assessed later in the process. This late consideration of 'how-to' knowledge had implications for successful adoption and implementation. In the cases where 'how-to' knowledge was given least priority during the early stages of 'initiation' and 'adoption decision', issues that should have been picked up when adoption decisions were being made came up at implementation trial and even once trust-wide implementation had begun. This resulted in (a) increased likelihood of technology rejection or protracted procurement decision at the 'adoption decision' stage, (b) delayed or incomplete implementation or discontinuance (following initial adoption) during the stage of 'implementation'.

Commercial suppliers and peer review publications were used as often as each other for 'principles' knowledge while noting potential supplier bias. Suppliers responded to preferences for theoretical knowledge by a highly professionalised user group. This is in contrast to individual consumers where marketing, as well as consumer interest is focused on 'awareness' and 'how-to' knowledge. ${ }^{15}$ Centralised (health system) structures were particularly underused as sources for 'principles' knowledge and were reported as less accessible and less relevant to the local context. Professional networks were widely used and comprised practice-based peer-mediated information about the innovations' relevance to the local setting.

The priority given to the three types of innovation knowledge depended on: (a) type of trust-teaching hospitals or research active organisations prioritised 'principles' knowledge; (b) professional background of those involved in adoption decisions-members of the medical profession tended to prioritise 'principles' and often ignored 'how-to' knowledge, while members of the nursing profession tended to balance the use of 'principles' and 'how-to' knowledge.

\section{Strengths and weaknesses}

The scale of the study and the real-time nature of investigating 38 adoption and implementation processes over a period of 18 months provided a rich data set. Our study is theory driven and comprises multisite comparative case studies, which overall enhance the generalisability of findings beyond the context of the specific sites studied. ${ }^{27}$ We explicitly studied cases of non-adoption and discontinuation after initial adoption, which are rarely included in innovation diffusion studies. We looked at centralised, organisational, professional and local influences in the process.

On limitations, the predefined sample in our study was not exhaustive by trust type, though sufficiently diverse (table 1). At the same time, a common barrier to adoption (availability of funding) was 'controlled for' in this sample, allowing other factors during adoption decision to be explored. We were not able to follow 
implementation past the end of August 2010 and therefore do not have information on routinised use of the implemented technologies.

\section{Important differences in results with other studies}

While innovation literature in commercial sectors considers the types of innovation knowledge in technology adoption by individuals,${ }^{15}$ the role of these types of knowledge in organisational decisions within the highly professionalised context of a healthcare system is missing. The types of trusts, and the professional background of those involved in technology adoption decisions influenced how technologies were adopted and implemented in our study. These factors had bearing on the type of innovation knowledge used and timing of this knowledge utilisation. These findings build on literature that identifies interactions between the innovation, local actors, leadership and multilevel contextual factors ${ }^{10}$ 12 38-40 shaping the technology adoption process. Furthermore, our study demonstrates an impact of variable use of knowledge on 'successful' adoption decisions. The role of professional backgrounds in this process builds on work by Ferlie and colleagues ${ }^{5}$ who looked at the adoption of guidelines in four areas of clinical care and found that there are cognitive, social and epistemic barriers to knowledge flow among health professionals.

Data from all cases show that 'how-to' knowledge was important in the innovation process, not only operationally but also strategically, spanning issues of structural and cultural compatibility, and sustainability. This broader conceptualisation better aligns the construct with the complex adjustments that are often needed in organisational settings. ${ }^{629}$ Our findings suggest a more prominent focus for 'how-to' knowledge in the future, by both practitioners and researchers. ${ }^{41} 42$

\section{Implications for clinicians and policymakers}

Health systems remain to fully exploit patient benefit through sustainable use of evidence-based technologies. ${ }^{43} 44$ Balancing 'principles' and 'how-to' knowledge at the early stages of the innovation process will provide decision makers with clinical and financial justification for innovations, as well as practical implementation guidance. Learning from discontinued adoption or failed implementation of technologies is as important as success stories.

Data from all our cases show that acceptance of innovation knowledge depended on the perceived credibility of the source. Current health policy practice, as outlined in the introduction, is implicitly founded on the notion that health professionals do access primarily centralised sources to acquire knowledge about innovative technologies. Our findings differ, emphasising a more prominent role of local and peer-mediated sources, such as professional associations, local practice trials, experiences of peers and local experts. Given the patterns of knowledge exchange among our respondents, investing in horizontal knowledge exchange to complement 'top down' knowledge transfer is indicated.
Appraising the local environment for structural and cultural compatibility of the technologies is essential along with evidence for efficacy and cost-effectiveness to avoid waste of valuable resources and potential to cause inadvertent harm from inappropriate implementation.

There are implications here of who is involved in the innovation adoption process and the role played by key decision makers. Since healthcare services are increasingly configured as multiprofessional team activities ${ }^{45}$ organisational innovation adoption decisions need also to account for local attitudes to evidence of different professional groups. Policy makers need to reconcile the need for central guidance and quality standards with locally relevant practice-based evidence to contextualise the research in line with practical needs.

\section{Future research and unanswered questions}

More work is needed to understand how organisational priorities shape the perspective of organisational leaders and other key decision makers as regards innovation knowledge. In particular, a better understanding of the dynamics in the late stages of the innovation process in organisations (implementation and routinisation) is needed. A study in progress funded by National Institute for Health Research Service Delivery \& Organisation (NIHR SDO) considers such issues in depth. ${ }^{46}$

A number of other questions remain unanswered. Future studies need to account for individual and organisational motivation to source evidence. Also, given that different professionals view different sources and types of evidence differently, how can these differences be reconciled? And who can play the role of 'evidence broker'? Finally, we need to account for wider influences of different health system structures (centralised tax based versus disaggregated 'market' systems) and how these shape use of evidence and, ultimately, innovation uptake.

Acknowledgements We thank the participating hospitals for supporting this work, and we thankfully acknowledge all respondents who participated in the study and kindly gave their time. We are also grateful to Sue Smalley from the Department of Health for project support and constructive feedback and Professor Charles Vincent from Imperial College Centre for Patient Safety and Service Quality for reviewing the draft manuscript. The authors acknowledge the United Kingdom Clinical Research Collaboration (UKCRC) who fund the National Centre for Infection Prevention and Management and the National Institute for Health Research Biomedical Research Centre at Imperial College London.

Contributors YK and RA conceived the idea for the paper, and collected and systematically analysed all data. All three authors interpreted the data. YK designed the initial study and drafted the article, RA contributed to study design and all three authors revised it critically for important intellectual content. All three authors approve the content of the manuscript submitted.

Funding This study is an independent study that was funded by the $\mathrm{DH}$. The $\mathrm{DH}$ influenced the execution of the study as follows: the award from $\mathrm{DH}$ came with an agreement in principle with the trusts to participate in the study. Access to the participating trusts in the first instance was via $\mathrm{DH}$ by means of an introductory letter sent by Sue Smalley from $\mathrm{DH}$. The trusts were then approached by a member of our research team. The researchers did provide update to $\mathrm{DH}$ on progress regards access and spend on technologies. The $\mathrm{DH}$ had no other interference in the design, execution and interpretation of findings.

Competing interests All authors have completed the Unified Competing Interest form at http://www.icmje.org/coi_disclosure.pdf (available on request 
from the corresponding author) and declare: no support from any organisation for the submitted work; no financial relationships with any organisations that might have an interest in the submitted work in the previous 3 years; no other relationships or activities that could appear to have influenced the submitted work.

Ethics approval Ethical approval was not required for the study under NHS research governance arrangements (letter dated 23 April 2009 by Hammersmith and Queen Charlotte's and Chelsea Research Ethics Committee). The research was classed as service evaluation by the chairman of the committee. Access to the participating trusts was via $\mathrm{DH}$ in the first instance through an introductory letter. The trusts were then approached by a member of our research team. The project lead and IPC teams in each trust further facilitated access to those involved in the decision-making, procurement and implementation of the selected technologies. Prior informed consent to join the study was obtained in writing by participating individuals. Yiannis Kyratsis (Author 1) and Raheelah Ahmad (Author 2) conducted the interviews, both experienced qualitative researchers with no prior relationship with the informants. Interviews were guided by a topic guide. All interviews, but one, were audio-recorded. Audio-recorded interviews were transcribed verbatim by professional transcribers and then checked by the researchers for accuracy. Primary data were anonymised and stored securely on password-protected computers prior to processing.

Provenance and peer review Not commissioned; externally peer reviewed.

Data sharing statement There are no additional unpublished data available.

\section{REFERENCES}

1. Darzi A. High Quality Care for All Department of Health. London, UK: TSO, 2008.

2. Blumenthal D. Stimulating the adoption of health information technology. N Engl J Med 2009;360:1477-9.

3. Cutler DM. Where Are the Health care Entrepreneurs? The Failure of Organizational Innovation in Health care. Chicago USA: University of Chicago Press, National Bureau of Economic Research Working Paper Series, 2010. No. 16030.

4. Berwick DM. Disseminating innovations in health care. JAMA 2003;289:1969-75.

5. Ferlie E, Fitzgerald L, Wood M, et al. The Nonspread of innovations: the mediating role of professionals. Acad Manag J 2005;48:117-34.

6. Greenhalgh T, Robert G, Macfarlane F, et al. Diffusion of innovations in service organizations: systematic review and recommendations. Milbank Q 2004:82:581-629.

7. Cooksey D. A review of UK health research funding. In: Treasury $\mathrm{H}$, ed. HM Treasury. London, UK: HMSO, 2006.

8. Department of Health. Report of the High Level Group on Clinical Effectiveness. London: Department of Health, 2007.

9. Clinical Effectiveness Research Agenda Group. An Implementation Research Agenda: A Report Prepared for the High Level Group on Clinical Effectiveness by the Clinical Effectiveness Research Agenda Group. London, UK: Clinical Effectiveness Research Agenda Group, 2008.

10. Rye CB, Kimberly JR. The adoption of innovations by provider organizations in health care. Med Care Res Rev 2007;64:235-78.

11. Nutley SM, Walter I, Davies HTO. Using Evidence-How Research Can Inform Public Services. Bristol: The Policy Press, 2007.

12. Robert G, Greenhalgh T, MacFarlane F, et al. Adopting and assimilating new non-pharmaceutical technologies into health care: a systematic review. J Health Serv Res Policy 2010;15:243-50.

13. Department of Health. Innovation Health and Wealth, Accelerating Adoption and Diffusion in the NHS. Leeds, West Yorkshire: Department of health NHS Improvement \& efficiency Directorate innovation and service Improvement, 2011:36.

14. Damanpour F, Schneider M. Phases of the adoption of innovations in organisations: effects of environment, organisation and top managers. Br J Manag 2006;17:21

15. Rogers EM. Diffusion of Innovations. 5th edn. New York: Free Press, 2003.

16. Van de Ven AH, Polley DE, Garud RA, et al. The Innovation Journey. Oxford, New York: Oxford University Press Inc, 1999.

17. Umscheid CA, Mitchell MD, Doshi JA, et al. Estimating the proportion of healthcare-associated infections that are reasonably preventable and the related mortality and costs. Infect Control Hosp Epidemiol 2011;32:101-14.

18. Ducel G, Fabry J, Nicolle L, eds. Prevention of hospital-acquired infections: a practical guide. 2nd edn. Geneva, Switzerland: World Health Organization. World Health Organization 2002.
19. Scott RD. The Direct Medical Costs of Healthcare-Associated Infections in U.S. Hospitals and the Benefits of Prevention. Atlanta, USA: Centers for Disease control and prevention, 2009.

20. Klevens RM, Edwards JR, Richards CL Jr, et al. Estimating health care-associated infections and deaths in U.S. hospitals, 2002. Public Health Rep 2007;122:160-6.

21. Smyth ET, Mcllvenny G, Enstone JE, et al; Hospital Infection Society Prevalence Survey Steering Group. Four country healthcare associated infection prevalence survey 2006: overview of the results. $J$ Hosp Infect 2008;69:230-48.

22. Office for National Statistics. Health Statistics Quarterly 39. Surrey, UK: Palgrave Macmillan, 2008.

23. Pratt RJ, Pellowe C, Loveday HP, et al. The epic project: developing national evidence-based guidelines for preventing healthcare associated infections. J Hosp Infect 2001:47(Suppl 1):S3-4.

24. Department of Health. Clean Safe Care: Reducing Infections and Saving Lives. London, UK: Department of Health, 2008:40.

25. Kyratsis $\mathrm{Y}$, Ahmad R, Holmes A. Understanding the Process of Innovation Adoption in 12 NHS Trusts-Technology Selection, Procurement and Implementation to Help Reduce HCAls. London: Department of Health, 2010:331. http://www.wp.dh.gov.uk/hcai/files/ 2011/07/Technology-Adoption-Study_DH-Approved_FINAL-FULLREPORT Feb-2011 including-Acknlowledgments.pdf

26. Eisenhardt KM. Building theories from case study research. Acad Manag Rev 1989;14:532-50.

27. Fitzgerald L, Dopson S. Comparative Case Study Designs: their utility and development in organizational research. In: Buchanan D, Bryman A, eds. The SAGE Handbook of Organizational Research Methods. London, UK: SAGE Publications Ltd, 2009:465-83.

28. Lee T. Using Qualitative Methods in Organizational Research. Thousand Oaks CA, USA: SAGE Publications, Inc, 1998.

29. Meyer AD, Goes JB. Organizational Assimilation of innovations: a Multilevel contextual analysis. J Acad Manag 1988;31:897-923.

30. Brechin A, Siddell M. Ways of knowing. In: Gomm R, Davies C, eds. Using Evidence in Health and Social Care. Buckingham: Open University Press, 2000.

31. Bradley EH, Curry LA, Devers KJ. Qualitative data analysis for health services research: developing taxonomy, themes, and theory. Health Serv Res 2007;42:1758-72.

32. Atun RA, Kyratsis I, Jelic G, et al. Diffusion of complex health innovations-implementation of primary health care reforms in Bosnia and Herzegovina. Health Policy Plan 2007;22:28-39.

33. Pope $\mathrm{C}$, Ziebland S, Mays N. Analysing qualitative data. BMJ 2000;320:114-16.

34. Sofaer S. Qualitative methods: what are they and why use them? Health Serv Res 1999;34:17.

35. Barbour RS. Checklists for improving rigour in qualitative research: a case of the tail wagging the dog? BMJ 2001;322:1115-17.

36. Mays N, Pope C. Qualitative research in health care. Assessing quality in qualitative research. BMJ 2000;320:50-2.

37. Barry CA, Britten N, Barber N, et al. Using reflexivity to optimize teamwork in qualitative research. Qual Health Res 1999;9:26-44.

38. Ferlie E, Fitzgerald L, Woods M. Getting evidence into clinical practice: an organisational behaviour perspective. J Health Serv Res Policy 2000;5:6.

39. Dopson S, FitzGerald L, Ferlie E, et al. No magic targets! Changing clinical practice to become more evidence based. Health Care Manage Rev 2002;27:35-47.

40. Denis JL, Hébert $\mathrm{Y}$, Langley A, et al. Explaining diffusion patterns for complex health care innovations. Health Care Manage Rev 2002;27:60-73.

41. Gladwin J, Dixon RA, Wilson TD. Rejection of an innovation: health information management training materials in east Africa. Health Policy Plan 2002;17:354-61.

42. Fitzgerald L, Ferlie E, Wood M, et al. Interlocking interactions, the diffusion of innovations in health care. Hum Relat 2002;55:1429-49.

43. Halladay M, Bero L. Implementing evidence-based practice in health care. Publ Money Manag 2000;20:43-50.

44. Sheikh A, Cornford T, Barber N, et al. Implementation and adoption of nationwide electronic health records in secondary care in England: final qualitative results from prospective national evaluation in "early adopter" hospitals. BMJ 2011;343:d6054.

45. Meads G, Ashcroft J, Barr H, et al. The Case for Interprofessional Collaboration in Health and Social Care. Oxford UK: Wiley-Blackwell, 2005.

46. Kyratsis $\mathrm{Y}$, Ahmad R, Holmes A. Making sense of evidence in management decisions: the role of research-based knowledge on innovation adoption and implementation in healthcare. Study protocol. Implementation Science 2012;7:22 doi:10.1186/1748-59087-22 